\title{
O DESENVOLVIMENTO PROFISSIONAL CORRESPONSÁVEL DE PROFESSORES DE LÍNGUA MATERNA COMO PROPOSTA DE INTERCÂMBIO ENTRE ACADEMIA E MERCADO DE TRABALHO ${ }^{1}$
}

Liane Batistela Kist²

\begin{abstract}
Resumo: A proposta que aqui se apresenta tem por objetivo investigar o Desenvolvimento Profissional Corresponsável (DPC), especialmente do professor de Língua Materna (LM), como possibilidade de intercâmbio entre academia e mercado de trabalho. O DPC consiste em uma concepção triádica de profissionalização articulando, em bases de aliança e confiança recíproca, três lugares: Academia, Graduação e Mercado, sendo irredutível à simples soma de duas díades, como não raro se observa em iniciativas de formação inicial ou continuada. O DPC é um dos conceitos subjacentes à Teoria Holística da Atividade (THA) de Richter (2011), cuja matriz diz respeito à inseparabilidade entre conduta, conceito e valor no exercício profissional, ordenados de forma sistêmica através de um conjunto de conceitos teóricos que permitem ao professor organizar seu trabalho. Para realizar a investigação, partiu-se da análise de algumas seções do relatório de atividades do Subprojeto Letras Português integrante do Programa Institucional de Bolsas de Iniciação à Docência - PIBID. Tendo em vista que, para se implementar um DPC, seja necessária uma aliança profissional alicerçada num elo de confiança e na adoção de um paradigma de trabalho consensual entre capacitação inicial e em-serviço, buscou-se identificar no PIBID/Português a possibilidade de um modelo formativo capaz de ancorar os fatores necessários ao desenvolvimento profissional de professores de LM. Como método investigativo, foi utilizada a análise de indícios discursivos, através do paradigma indiciário de Ginsburg (1989). Em linhas gerais, pode-se dizer, de modo geral, que o PIBID/Português revelou aspectos positivos no tocante à inseparabilidade entre conduta, conceito e valor no exercício profissional e, portanto, indícios de um DPC no contexto de implementação, já que proporcionou, de modo preciso, uma triangulação ou, dito de outra forma, uma horizontalização profissional com o objetivo de proceder à capacitação integrada inicial e em-serviço, condição sine qua non para a formação de uma aliança profissional, no caso do ensino de língua materna, uma aliança linguodidática.
\end{abstract}

Palavras-chave: Linguística Aplicada, Teoria Holística da Atividade, Desenvolvimento Profissional Corresponsável

\begin{abstract}
This study investigates the possibilities and challenges to the Co-responsible Professional Development (DPC, in portuguese), specially, from the teacher of first language (LM, in portuguese). The DPC, is a triadic conception of professionalization that articulate, based on aliance and reciprocal confidence, three contexts: Academy, Graduation and Market, considering irredutible the sum from only two diades, as normally is observed in iniciatives of inicial or continued formation. The DPC is one of the basic concepts from the Holistic Activity Theory (THA, in portuguese) from Richter (2011) which pattern concerns the

\footnotetext{
1 Este artigo consta de um recorte da pesquisa, ainda em fase inicial, "Indícios discursivos do desenvolvimento profissional corresponsável em um programa de formação docente à luz da teoria holística da atividade" como requisito para obtenção do título de doutorado em Letras pelo Programa Pós-Graduação em Letras da Universidade Federal de Santa Maria. A referida pesquisa doutoral está sendo desenvolvida pela autora em conjunto com seu orientador, Prof. Dr. Marcos Gustavo Richter que assina conjuntamente o presente artigo.

2 Licenciada em Letras/Português, Mestre em Educação, Aluna do Programa de Pós-Graduação em Letras da Universidade Federal de Santa Maria - doutorado em Estudos Linguísticos/PPGL/UFSM. Professora-Pesquisadora da Universidade Aberta do Brasil/UFSM. Email: lianekist@yahoo.com.br.
} 
inseparability among conduct, concept and quality in the professional practice, ordered in a sistemic way through a conjunct of theoretical concepts that allow teachers to organize their job. The development of the investigation starts out from an analysis of the activities reports from the Portuguese Language Course Subproject that integrates the Institutional Scholarship Program of Introduction to Teaching - PIBID (in portuguese). Owing that, to implement a DPC, a professional alliance is necessary, stablishing a link of confidence and in the adoption of a paradigm of consensual work between initial and in-service capacitation, this study begins by analysing the PIBID/Portuguese as a formative model able to anchor the necessary elements to the professional development of first language teachers. Based on the analysis of discursive evidences, using the indiciary paradigm from Ginsburg (1989), it is possible to say, in a general way, that PIBID/Português revealed positive aspects in relation to the inseparability among conduct, concept and quality in the professional practice and, so, evidences of a DPC in the implementation context, since it jointly provided the organization of interventions to be realized by the group (framework), the sistematic of evalution and necessary adjustments to the development of the scheduled and realized activities and, the reflection about the professional behavior and the ethic co-responsible formation of first language teachers.

Keywords: applied linguistics, Holistic Activity Theory, Co-responsible Professional development

\section{Considerações iniciais}

A proposta que aqui se apresenta tem por objetivo investigar 0 Desenvolvimento Profissional Corresponsável (DPC), especialmente do professor de Língua Materna (LM), como possibilidade de intercâmbio entre academia e mercado de trabalho, partindo-se na análise de indícios discursivos no relatório de atividades do Programa Institucional de Bolsas de Iniciação à Docência/Português - PIBID, à luz da Teoria Holística da Atividade (THA). A perspectiva e também justificativa desse estudo está associada, por um lado, a um quadro de pesquisa bastante recente no que diz respeito ao PIBID/Português $^{3} \mathrm{e}$, por outro, à necessidade permanente de pesquisas e investigações no campo da linguística aplicada, sobretudo, na formação de professores de língua materna, tanto em situação inicial, como em-serviço na área.

A esse respeito, destacam-se estudos de Zeichner (2010) e Mizukami (2013), os quais apontam a necessidade de conexões mais sólidas entre universidadeescola, tendo em vista o desenvolvimento profissional da docência.

Para Zeichner (2010, p. 487), decorre a necessidade de criação do que ele denomina de terceiro espaço, isto é: da constitutição de "espaços híbridos nos programas de formação inicial de professores que reúnem professores da Educação Básica e do Ensino Superior, e conhecimento prático profissional e acadêmico em

\footnotetext{
${ }^{3}$ Em recente busca por palavras-chave na Biblioteca Digital Brasileira de Dissertações e Teses, embora tenham sido localizados 11 trabalhos (10 em nível de mestrado e 01 em nível de doutorado) para a palavra-chave "PIBID", não foram encontrados, até a data da pesquisa, nenhuma investigação em nível de mestrado e/ou doutorado para a palavra-chave "PIBID/LP/Português". Pesquisa realizada na Biblioteca Digital Brasileira de Dissertações e Teses, disponível em: <http://bdtd.ibict.br/vufind/>. Acesso em 03 de agosto de 2015.
} 
novas formas para aprimorar a aprendizagem dos futuros professores". Acrescenta o autor que esses "terceiros espaços" poderiam reunir, de forma menos hierárquica, o conhecimento prático ao acadêmico de modo a promover a criação de novas oportunidades de aprendizagem para professores em formação.

\begin{abstract}
Da perspectiva das faculdades e das universidades, a solução para a desconexão entre universidade e escolas na formação de professores e na formação profissional continuada para professores da Educação Básica tem sido, habitualmente, tentar perceber maneiras melhores de trazer o saber acadêmico das faculdades e das universidades para os professores da Educação Básica. Esse tem sido um modelo de fora para dentro, no qual o saber está primordialmente entre os acadêmicos e não entre os professores da Educação Básica (...). A criação de terceiros espaços na formação de professores envolve uma relação mais equilibrada e dialética entre o conhecimento acadêmico e o da prática profissional, a fim de dar apoio para a aprendizagem dos professores em formação (ZEICHNER, 2010, p. 487).
\end{abstract}

Nessa mesma direção, Mizukami (2013, p.23-25) comenta que os processos de aprender a ensinar, de aprender a ser professor e de se desenvolver profissionalmente são lentos; iniciam-se antes do espaço formativo dos cursos de licenciatura e se prolongam por toda a vida, alimentados e transformados por diferentes experiências profissionais e de vida. Nesse sentido, constitui-se a escola como um local por excelência de aprendizagem e de desenvolvimento profissional da docência, tendo em vista proporcionar pelo menos três experiências: 1) conhecimento sobre os alunos, suas aprendizagens e seus desenvolvimentos; 2) conhecimento da matéria e dos objetivos do currículo; 3) conhecimento sobre como ensinar a matéria. A autora aponta a escola como lugar de construção de conhecimento da docência e inter-relação entre formação inicial e continuada assim como de desenvolvimento profissional da docência e de atitude investigativa.

$\mathrm{Na}$ esteira de modelos formativos ancorados em processos sistemáticos e organizados, encontra-se a THA, de Richter (2011), cuja premissa principal diz respeito à inseparabilidade entre conduta, conceito e valor no exercício profissional, ordenados de forma sistêmica através de um conjunto de conceitos teóricos que permitem ao professor organizar seu trabalho nos moldes de um paradigma consensual e compartilhado/apoiado por uma comunidade laboral e discursiva (enquadramento).

Fundamentada na Teoria dos Sistemas Sociais de Luhmann (2009), no Paradigma da Complexidade de Bateson (1986) e na Semiótica de Peirce (1977), a THA organiza-se em torno da concepção de sistema operacionalmente fechado e centrado no papel profissional. Essas operações se organizam em três níveis ordenados de forma crescente de acordo com seu grau de complexidade:

a) Constitutivo: diz respeito à construção e ao desenvolvimento da identidade e especificidade do sistema, isto é, da própria constituição do sistema;

b) Articulativo: refere-se ao gerenciamento das interfaces de acoplamento e manutenção da integridade do espaço próprio sistêmico; 
c) Exercitivo: está relacionado à produção dos eventos de entorno voltados à estabilidade e homeostase do ecossistema social.

Esses três níveis operacionais, grosso modo, fazem referência aos princípios de organização do trabalho em profissões regulamentadas ${ }^{4}$ e associam-se a um paradigma subjacente de seleções e decisões denominadas pela THA de enquadramento. Entre as seleções e decisões necessárias à organização do trabalho docente, encontram-se, em ordem crescente de complexidade, os fatores de atribuição, mediação e controle, os quais, ao operarem consensualmente, viabilizam um DPC.

A perspectiva do DPC está presente nas últimas versões da THA ${ }^{5}$ e está relacionada à ideia de que uma formação profissional adequada é aquela que alinha, no caso da formação de professores de Língua Materna, professores em situação inicial de formação, professores em serviço na Educação Básica e professores em serviço nas Instituições Formadoras.

Por outro lado, encontra-se o Programa Institucional de Bolsa de Iniciação à Docência (PIBID), cujo objetivo central está assentado na elevação da qualidade da formação inicial de professores nos cursos de licenciatura, promovendo a integração entre educação superior e educação básica.

Nesse sentido, e levando-se em consideração que, para se implementar um DPC, seja necessária uma aliança profissional entre capacitação inicial e emserviço, é que se insere esta investigação com intuito de se analisar o PIBID/Português como um lugar possível para uma forte articulação entre universidade e escola.

\section{A formação de professores de língua materna}

Historicamente, o ensino de língua portuguesa (LP), como língua materna, tem sido alvo de discussões, as quais encerram sua estreita relação com o fracasso vivenciado na educação brasileira como um todo. No centro das discussões, estão questões que giram, sobretudo, em torno dos conteúdos a serem ensinados e da forma como tratá-los em sala de aula, o que gravita inevitavelmente na seleção de normas e regras, isto é, no ensino da gramática tradicional como premissa para o domínio da norma culta.

\footnotetext{
${ }^{4}$ Por profissões regulamentadas, ancorando-se aqui nas palavras de Steinhilber (1996), destacam-se aquelas que possuem seus respectivos Conselhos Profissionais, reguladores e fiscalizadores do exercício profissional; e não regulamentadas aquelas que, apesar de serem reconhecidas e legalmente amparadas e, apesar de possuírem escolas de formação autorizadas por autoridades competentes, não podem desfrutar de um exercício profissional regulado pelos respectivos profissionais, isto é, por seus pares.

5 Atualmente a Teoria Holística da Atividade (THA) encontra-se na versão 4.3, mas sua origem (Versão 1.0) remonta os anos 2000. Para mais informações sugere-se a leitura do texto: KADER, Carla Callegaro Corrêa. Um estudo dos fatores de atribuição em textos acadêmicos de Letras e Psicologia à luz da Teoria Holística da Atividade e da Linguística de Corpus. Tese (Doutorado em Estudos Linguísticos) - Universidade Federal de Santa Maria, Santa Maria, 2014.
} 
Via de regra, isso reflete, nas escolas, em condutas pautadas pelo trabalho exaustivo com a gramática normativa tanto em seu aspecto prescritivo (determinação de normas e regras), como em seu aspecto analítico (análise de funções e de elementos) (BEZERRA, 2005).

Em muitos dos casos, práticas descontextualizadas, produzidas a partir da reprodução de exercícios de fixação de normas e regras da norma culta, têm preenchido os espaços nas aulas de língua. A segundo plano, relega-se o tratamento efetivo da língua desdobrada especialmente no ensino da leitura e da escrita na escola 6 .

A esse cenário, acrescenta-se o problema relativo ao reconhecimento primeiro da docência como profissão regulamentada. Em relação ao resultado do serviço prestado, pensando em especial no serviço prestado pelo professor de línguas, Richter (2011) considera que, embora seja legítimo o binômio emancipação/competência, não é regra afirmar que toda a atuação docente é desprovida de qualidade em razão da ausência de uma regulamentação/emancipação profissional:

Embora a desidentificação com um grupo em si mesma não impeça o trabalho satisfatoriamente realizado, um olhar crítico lançado às práticas discursivas e materiais das profissões autogeridas deixa entrever que a identificação de um indivíduo com seu grupo de referência é acompanhada de identificação mútua entre seus membros - o que favorece a emergência e manutenção do espírito corporativo, repercutindo na organização da classe e, por fim, na qualificação da atividade (RICHTER, 2011, p.112).

Todavia, vale ressaltar que um sentimento de pertença e referência a um grupo profissional regulamentado/emancipado confere não só garantias profissionais mais estáveis (por conta da existência de conselhos fiscais e regulatórios corporativos), mas também a possibilidade de uma atuação profissional assentada em saberes teóricos e metodológicos normatizados e regulamentados por instâncias especializadas e legítimas.

O trabalho formativo em profissões juridicamente ordenadas resulta na internalização, pelo acadêmico, de uma série de parâmetros ordenadores que configuram campo e limites de intervenção, objetivos, condições e características da atividade, direitos e deveres recíprocos na prestação de serviços. E, sobretudo, confere, a partir do lugar social ocupado, um senso de identidade e autoestima. (RICHTER, 2011, p.113).

A respeito de parâmetros ordenadores, no caso do ensino de língua materna, da adoção de procedimentos linguodidáticos pautados em perspectivas teóricas capazes de fundamentar um ensino sociointeracionista, Antunes (2003) ressalta

\footnotetext{
${ }^{6}$ Embora o percurso metodológico assumido nessa investigação esteja fazendo uma crítica ao ensino da gramática, a postura aqui adotada não tem por objetivo extinguir o trabalho com a gramática. $\mathrm{A}$ esse respeito coaduna-se com Zuin \& Reyes (2010, p.25): Saber gramática é importante, mas não como análise fragmentada de frases sem um determinado contexto. A questão fundamental que se põe por trás da aprendizagem da língua é, assim, o sentido e a significação, pois o domínio de uma língua é o resultado de práticas significativas e contextualizadas de seu uso.
} 
certa incompreensão ou restrição da parte dos professores quando o assunto requer, em especial, associação entre teoria e prática. Se por um lado os professores revelam carência por questões práticas aliadas ao descontentamento com as explicações teóricas que lhe são acessíveis; por outro revelam certo desinteresse ou até mesmo incompreensão acerca do que seja teoria e prática e, portanto, sobre a interdependência existente entre elas ou ainda uma aparente acomodação reveladora da postura de muitos, os quais esperam passivamente que alguém diga o que eles precisam fazer. Nessa direção a autora acrescenta:

\begin{abstract}
Não pode haver uma prática eficiente sem fundamentação num corpo de princípios teóricos sólidos e objetivos. Não tenho dúvidas: se nossa prática de professores se afasta do ideal é porque nos falta, entre outras muitas condições, um aprofundamento teórico acerca de como funciona o fenômeno da linguagem humana. O conhecimento teórico disponível a muitos professores, em geral, se limita a noções e regras gramaticais apenas, como se tudo o que é uma língua em funcionamento coubesse dentro do que é uma gramática. Teorias linguísticas do uso da prosódia, da morfossintaxe, da semântica, da pragmática, teorias do texto, concepções de leitura, de escrita, concepções, enfim, acerca do uso interativo e funcional das línguas, é o que pode embasar um trabalho verdadeiramente eficaz do professor de português (ANTUNES, 2003, p. 40-41).
\end{abstract}

Em consenso com Antunes (2003), Richter (2005, p.10) destaca que ao lado do mal-estar docente, obstáculo endêmico para os professores de línguas na educação básica, "haja vista a notória e crônica falta de perspectivas quanto ao exercício condigno da profissão, em todos os seus aspectos", "as mudanças nas práticas docentes, bem como o trabalho de fundamentação dessas novas práticas, ou seja, a formação de conceitos na esfera profissional" contribuem sobremaneira no agravo do quadro da formação de professores.

Para o autor, o acadêmico-docente, acrescido aqui do professor em-serviço, não raro, quando desprovido das condições propícias para a formação de conceitos específicos em determinada área da prática pedagógica, tenta eventualmente inovar por simples intuição ou tentativa-e-erro irrefletidamente conduzida. Essa conduta para Richter é mais do que um motivo para se pensar na reorientação da formação inicial e também continuada a partir de um Modelo Holístico de Formação Docente.

\title{
O enquadramento de trabalho e o DCP na Teoria Holística da Atividade
}

A THA, como uma teoria da atividade, emerge do intercâmbio das relações que de um lado centram-se numa preocupação com a formação de professores e de outro na conquista por um espaço profissional emancipado e regulamentado para professores de línguas:

(...) ao se repensar a formação docente inicial e continuada, impõe-se um novo enquadramento, que aqui propomos: um Modelo Holístico de Formação Docente. Neste, os instrumentos a serem utilizados para a análise do discurso professoral deverão equacionar o eu-docente em termos de uma representação identitária situada entre outras e 
mediada pelas singularidades discursivas associadas (RICHTER, 2005, p. 07 - com base em GEE, 19997).

A THA de Richter (2011), de modo geral, encontra-se alicerçada em paradigmas formativos pautados nessa articulação entre os diferentes níveis de uma cadeia profissional através de uma relação triádica estabelecida na interface entre Academia (alunos e professores) e Mercado (professores de escola).

Para o autor, Richter (2011), a grande maioria dos professores de línguas, no contexto brasileiro, tende grosso modo a adotar acriticamente os mesmos procedimentos didáticos inconsistentes com os quais foram escolarizados, com isso, insistindo em fazer a reflexão preceder a ação, o que inevitavelmente leva à acrasia (dissociação entre discurso e prática). Nesse sentido, a THA revoluciona essa concepção ao propor o caminho inverso (a ação consensual precedendo a reflexão). Ou seja, assim como em profissões tipicamente regulamentas, o autor defende a formação de uma identidade sistêmica construída sobre uma arquitetura consistente e uniforme de saberes teóricos e metodológicos, sustentadora, normatizadora e reguladora das diversas intervenções profissionais, isto é, sobre princípios de organização do trabalho docente.

Esses princípios e normas dizem respeito, sobretudo, ao paradigma de seleções e decisões necessárias ao exercício profissional docente e, na THA, recebem 0 nome de enquadramento. Obedecendo a uma ordem crescente de complexidade, a THA postula para a organização coletiva do trabalho especializado três pilastras denominadas fatores de atribuição, de mediação e de controle.

Por fatores de atribuição, entende-se o conjunto de variáveis centradas nas noções de papeis sociais, tais como o lugar onde a atividade profissional é exercida, as tarefas a serem executas, as bases curriculares e jurídicas da tarefa exercida, os modelos de comportamento almejados, seus respectivos contextos e papeis dos sujeitos envolvidos (professor e aluno) e ainda a noção de referência e pertença grupal. Nas palavras de Richter (2011), os fatores de atribuição compõem o fundo sociointerativo dos eventos de intervenção especializada.

A mediação, em linhas gerais, diz respeito aos procedimentos profissionais em si e está organizada em torno de três metafatores: os recursos materiais e tecnológicos disponíveis aos sujeitos envolvidos (professores e alunos); as estratégias concretas realizadas tanto pelos docentes quanto pelos discentes (ambos os sujeitos envolvidos no processo) e os conceitos, ou seja, o conhecimento tanto teórico quanto prático.

Lado a lado com a mediação, encontra-se o fator de controle tripartido em objeto, monitoramento e regulação jurídica, os quais atendem, grosso modo, às possibilidades de acompanhamento e aferição das expectativas pretendidas e efetivamente alcançadas.

\footnotetext{
7 GEE, J. P. Social linguistics and literacies: ideology in Discourses. 2 ed. London/Philadelphia: The
} Farmer Press, 1999. 
De acordo com o modelo formativo de Richter (2011), o enquadramento é o que garante a tomada de decisão e seleção conscientes e ancoradas em um paradigma alinhado com perspectivas teórico-práticas próprias de cada área de conhecimento.

ENQUADRAMENTO

\begin{tabular}{|c|c|c|}
\hline FATORES DE ATRIBUIÇÃO & $\begin{array}{l}\text { FATORES DE } \\
\text { MEDIAÇÃO }\end{array}$ & $\begin{array}{l}\text { FATORES DE } \\
\text { CONTROLE }\end{array}$ \\
\hline $\begin{array}{l}\text { - conjunto de variáveis } \\
\text { centradas nas noções } \\
\text { de papeis sociais; } \\
\text { - tarefas a serem } \\
\text { executas; } \\
\text { - bases curriculares e } \\
\text { jurídicas da tarefa } \\
\text { exercida; } \\
\text { - modelos de } \\
\text { comportamento } \\
\text { almejados; } \\
\text { - contextos e papeis dos } \\
\text { sujeitos envolvidos } \\
\text { (professor e aluno); } \\
\text { - noção de referência e } \\
\text { pertença grupal. }\end{array}$ & $\begin{array}{l}\text { - procedimentos } \\
\text { profissionais em si; } \\
\text { - recursos materiais e } \\
\text { tecnológicos disponíveis } \\
\text { aos sujeitos envolvidos } \\
\text { (professores e alunos); } \\
\text { - estratégias concretas } \\
\text { realizadas tanto pelos } \\
\text { docentes quanto pelos } \\
\text { discentes (ambos os } \\
\text { sujeitos envolvidos no } \\
\text { processo); } \\
\text { - conceitos, ou seja, o } \\
\text { conhecimento tanto teórico } \\
\text { quanto prático. }\end{array}$ & $\begin{array}{l}\text { - possibilidades de } \\
\text { acompanhamento } \\
\text { e aferição das } \\
\text { expectativas } \\
\text { pretendidas e } \\
\text { efetivamente } \\
\text { alcançadas. }\end{array}$ \\
\hline
\end{tabular}

Uma formação docente desenvolvida a partir de um enquadramento de trabalho, conforme Cavichioli (2012), também pode postular os princípios fundamentais de organização para a prática de ensino. Em outras palavras, segue a autora, a proposta de enquadramento instrumentaliza o professor em situação inicial de formação uma concepção teórico-metodológica selecionada a priori (um paradigma) acerca dos fatos pertinentes à atuação em uma futura atividade profissional, tornando esse (futuro) docente capaz de eliminar os fenômenos pseudossistêmicos $^{8}$, que por ventura venham a afetar negativamente 0 desenvolvimento de suas atividades.

Essa perspectiva de enquadramento, portanto, está relacionada a uma lógica de paradigmação, isto é, de organização do trabalho, o que, no caso da profissão docente, só pode ser alcançado mediante uma formação alicerçada numa tríplice relação de aliança e confiança entre academia, graduação e escola, denominada por Richter (2015), na THA, de Desenvolvimento Profissional Corresponsável (DPC).

Em outras palavras, somente através de um DPC, garantido pela formação e/ou capacitação integrada inicial e em-serviço, é que se pode pensar, à luz da THA,

${ }^{8}$ No âmbito da perspectiva de enquadramento proposto pela THA e no caso do professor de língua materna, pode-se se considerar como fenômenos pseudossistêmicos aqueles que fazem parte das atividades de ensino de língua portuguesa, mas que ocasionalmente ou com frequência não obedecem ao paradigma sociointeracionista. 
numa aliança laboral consistente com vistas à construção de um papel profissional docente sólido que alinhe atividades-fim e atividades-meio ${ }^{9}$.

\section{A proposta federal pautada pelo Programa Institucional de Bolsa de Iniciação à Docência (PIBID)}

Problemas como relações teoria-prática, formação acadêmica, especialmente, no contorno do trabalho na escola, historicamente, têm sido colocados como desafios para a estrutura e dinâmica dos currículos dos cursos de formação de professores nas graduações no ensino superior (GATTI et.al., 2014).

$\mathrm{Na}$ tentativa de contribuir com a diminuição de pelo menos alguns desses problemas é que, em 2007, é criado o PIBID, cuja intenção estava associada ao desejo de se "fomentar a iniciação à docência com a finalidade de melhor qualificála, mediante projeto específico de trabalho e concessão de bolsas, abrangendo as diferentes áreas do conhecimento que fazem parte do currículo da educação básica" (GATTI et.al., 2014).

A proposta, a rigor, apresenta-se bastante positiva na medida em que considera a escola de educação básica como espaço de formação tanto para professores em formação inicial (alunos de cursos de licenciatura), quanto para professores em serviço nos sistemas básicos de ensino, os quais atuam como supervisores dos alunos de licenciatura, e ainda para os professores de cursos de licenciatura dos sistemas superiores de ensino que, a seu turno, atuam como coordenadores de área.

O modelo do programa parece apontar para a possibilidade de uma forte interação entre sistemas superiores de formação e escolas de educação básica com vistas à participação igualitária em ações formativas de professores em dimensões reais e concretas, isto é, mais próximas da realidade do professor e do seu campo de atuação profissional através de processos sistemáticos e organizados de inserção no ambiente escolar.

A proposta em questão responde aos encaminhamentos propostos pela Lei № 9.394/96 e a modelos de formação profissional fortemente pautados pela articulação não só entre teoria e prática mas entre profissionais que atuam em diferentes níveis da cadeia profissional. No caso da cadeia docente, entre os profissionais que atuam nas agências formadoras como professores, em especial

\footnotetext{
${ }^{9}$ De acordo com Richter (2015), atividades-fim são aquelas centralizadas num objeto ou motivo, no caso da THA, estão relacionadas às atividades dos profissionais da academia, profissionais do mercado e clientela; enquanto que as atividades-meio estão centralizadas em recursos humanos, ou seja, profissionais da academia, profissionais do mercado e graduandos. RICHTER, Marcos Gustavo. Questionamentos para o Desenvolvimento Profissional Corresponsável: DPC e Enquadramento. Material inédito. Universidade Federal de Santa Maria, 2015.
} 
professores-pesquisadores ${ }^{10}$, professores iniciantes e professores em atuação no mercado de trabalho (nas escolas).

\section{Quadro metodológico}

No que diz respeito às escolhas metodológicas desta investigação, optou-se inicialmente pela abordagem qualitativa, pelo estudo de caso e pelo paradigma indiciário como método de seleção e análise do corpus constituído pelo relatório de atividades do PIBID/Português.

Essa investigação não teve por intenção a utilização de metodologias que se apoiam em medidas operacionais, cuja intensidade pode ser traduzida em números, conforme Gatti (2002), mas sim na obtenção de dados a partir das experiências vivenciadas pelos sujeitos envolvidos com as atividades relacionadas ao PIBID/Português, por isso a escolha pela abordagem qualitativa.

Dependendo da questão estudada, a abordagem será quantitativa ou qualitativa. Elas podem até ser complementares, se o estudo assim o exigir. E preciso saber como tratar o problema que se está estudando e quais são os recursos metodológicos apropriados a esse tratamento (LÜDKE; 2006, p.420-421).

Quanto ao estudo de caso, coaduna-se com Stake (2007) ao apontar que se estuda um caso quando se tem um interesse muito especial sobre ele, quando se buscam os detalhes da interação em questão em seu próprio contexto. $O$ autor acrescenta ainda que o estudo de caso é o estudo da particularidade e da complexidade de um caso singular com o intuito de compreender suas atividades em circunstâncias importantes. No caso dessa investigação, trata-se da compreensão das atividades formativas desenvolvidas no âmbito do PIBID/Português para professores de língua materna, em especial, em situação de formação inicial e emserviço.

Em relação ao paradigma indiciário, tomou-se por base a proposta de Ginsburg (1989), que remonta a experiência de diferentes áreas da ciência, no século XIX, na busca pela apreensão qualitativa do objeto através da observação do detalhe em detrimento à observação daquilo que é particularmente mais conspícuo. Conforme o autor, a proposta está assentada em "um método interpretativo centrado sobre os resíduos, sobre os dados marginais, considerados reveladores" (GINSBURG, 1989, p. 149).

Nesse caso o que se propõe, à luz do paradigma indiciário, é uma revisão pormenorizada dos indícios discursivos reveladores de possíveis relações estáveis passíveis de serem consideradas como sinalizadoras de um DPC no relatório de

\footnotetext{
${ }^{10}$ Ressalta-se aqui o compromisso das Instituições de Ensino Superior não só com atividades de ensino, mas com atividades de pesquisa e extensão. "As universidades gozam de autonomia didático-científica, administrativa e de gestão financeira e patrimonial, e obedecerão ao princípio de indissociabilidade entre ensino, pesquisa e extensão" (BRASIL, 1988, Art. 207).
} 
atividades do PIBID/Português ${ }^{11}$. Para o levantamento dos indícios discursivos no relatório, partiu-se da análise das seções do relatório relativas à descrição dos impactos das ações/atividades do projeto na: formação de professores; licenciaturas envolvidas, educação básica, pós-graduação e escolas participantes; às contribuições para as licenciaturas da IES e às considerações finais e perspectivas do subgrupo apontadas no relatório.

\section{Análise e interpretação dos dados}

Considerando-se a descrição dos impactos das ações/atividades do projeto na: formação de professores; licenciaturas envolvidas, educação básica, pósgraduação e escolas participantes; as contribuições para as licenciaturas da IES e as considerações finais e perspectivas do subgrupo apontadas no relatório, foi possível identificar alguns segmentos linguísticos, tais como: "maior contato com a Escola Básica", "oportunidade de unir a teoria estudada (...) com a prática efetiva em sala de aula"; "mudanças significativas nas habilidades exploradas durante o ano letivo"; "validade de um trabalho colaborativo, entre professores de diferentes sistemas de ensino, para as partes envolvidas" e "aproximação efetiva entre os saberes, promovendo a formação continuada."

No segmento "maior contato com a Escola Básica" e, ainda, conforme aponta o relatório, "com o cotidiano e organização escolar" em razão das ações/atividades do projeto para a formação de professores, licenciaturas envolvidas, educação básica, pós-graduação e escolas participantes, detectou-se, inicialmente, o quanto a relação de proximidade entre universidade e escola se reveste de fundamental importância para o processo de formação de professores, sobretudo, a formação inicial.

Kist (2007), em pesquisa sobre a importância do estágio curricular como ponto de contato entre universidade e escola, apontou, nos relatos dos estagiários de cursos de licenciatura, essas mesmas preocupações:

A grande maioria dos estagiários apresenta uma série de preocupações relacionadas a primeira experiência em sala de aula como professor, ou seja, sobre o fato de ter que "dar aula pela primeira vez", entre as quais destacamos: expectativa em relação à aceitação e ao respeito da turma pelo estagiário, insegurança em relação aos procedimentos, às atitudes e às posturas a serem adotadas em sala de aula, timidez, dificuldade em conduzir uma aula, em gerenciar o tempo na sala de aula, em se relacionar com os alunos, incluindo o fato de ser avaliado por eles e pela própria escola, "dar aula" na posição de estagiário, falta de experiência em conduzir situações inesperadas na sala de aula, como a reprovação dos alunos em relação à metodologia (KIST, 2007, p. 98).

\footnotetext{
${ }^{11}$ Cabe ressaltar no quadro metodológico aqui apresentado que o subprojeto PIBID/Português, objeto dessa investigação, no ano de referência do relatório de atividades (2014), estava composto por oito integrantes: uma coordenadora de área (professora do quadro efetivo de professores da IES participante), uma professora do quadro permanente de uma escola de educação básica do município sede do subprojeto e seis alunas do Curso de Licenciatura em Letras/Português da IES participante.
} 
Ou seja, nessas preocupações, constatou-se, mais uma vez, a importância das atividades do subgrupo, as quais proporcionaram uma primeira experiência docente aos futuros professores, a partir de um modelo de inserção escolar que permitiu a constituição de uma base mais segura para eles.

Já em relação à "oportunidade de unir a teoria estudada (...) com a prática efetiva em sala de aula" ou, como aponta o relatório, ver efetivados, na sala de aula, os estudos e as discussões realizadas por todos os participantes nas reuniões gerais, puderam ser ressaltadas pelo menos duas questões: primeiro, a superação da acrasia; segundo, a contramão da perspectiva de esvaziamento ou de distanciamento da universidade em relação ao mercado de trabalho.

Nas palavras de Richter (2015, p. 01), a acrasia está relacionada à "dissociação entre o pensar e o agir". Contudo, no caso do trabalho desenvolvido pelo subgrupo, percebe-se, na avaliação acima destacada, uma proposta que segue justamente a direção contrária. Ao alegar a congruência entre pensar e agir, o grupo assumiu a superação dessa mazela, invertendo a lógica da discrepância "entre o que a pessoa diz que pensa e assume e o que ela efetivamente pratica no contexto considerado".

Num segundo plano, essa avaliação também é reveladora da contramão de um discurso bastante comum, tanto para docentes em formação, quanto para docentes em serviço, de que o trabalho realizado, efetivamente, pela maioria dos cursos de formação, é dotado de um distanciamento crônico em relação ao mercado/contexto a que se destina.

Ao revelar a consonância entre o trabalho de planejamento, estudo e discussões, desenvolvido, de forma coletiva, nas reuniões e nas demais ações do grupo, a proposta do programa de língua materna conseguiu transpor a histórica alegação de distanciamento, conseguindo demonstrar sentido entre uma coisa e outra, isto é, entre o lugar conferido à universidade, na execução de atividades-meio, e o lugar da escola responsável pelas atividades-fim.

Outro indício de que, por meio das ações do programa, em especial na área de língua materna, foi possível identificar um DPC alicerçado numa relação linguodidática entre mercado e academia, pôde ser constatado na avaliação feita pelas alunas do subprojeto (BIDs), pela coordenadora de área e pela supervisora ao se referirem às "mudanças significativas nas habilidades exploradas durante o ano letivo", no caso, as habilidades dos alunos da escola participante.

Logo, avaliar como positivo o desenvolvimento de habilidades, como argumentação em textos orais e escritos, revela o quanto a aliança (linguodidática), entre mercado e academia, favoreceu a aprendizagem dos alunos da escola e o quanto à escola se mostrou disposta a trabalhar com gêneros dessa natureza.

Embora os PCN e as OCEM tenham sinalizado, há mais de uma década, a necessidade do trabalho com gêneros textuais, incluindo os orais, essa não costuma ser uma prática rotineira nas escolas, não só pela falta de capacitação dos 
professores para a realização desse trabalho, mas também pela própria ausência desses textos e atividades dessa ordem na grande maioria das coleções didáticas disponíveis nas instituições escolares.

Quanto à alegação de que a proposta do grupo de língua materna provou a "validade de um trabalho colaborativo, entre professores de diferentes sistemas de ensino, para as partes envolvidas", cabe destacar uma perspectiva já defendida por Richter (2015) no que diz respeito às relações binárias e ternárias nos processos formativos. A defesa segue na direção de que uma relação binária (professores da academia + alunos de licenciatura) pouco avança, do ponto de vista qualitativo e integral, o quadro formativo do futuro professor, sendo necessárias relações do tipo ternárias. Ou seja, sugere-se que

a superação da acrasia e a construção de um ego profissional não fragmentado e fundamentado no princípio de enquadramento devem desacoplar as dimensões do imaginário e do simbólico, introduzindo na aliança binária um terceiro elemento, qual seja, a aliança por parte do profissional do mercado, isto é, da atividade-fim, resultando a relação triádica de formação profissional que a THA denomina desenvolvimento profissional corresponsável (RICHTER, 2015, p. 101-102).

A esse respeito, acrescentam-se as palavras de Capelle \& Silva (2013) a respeito da teoria da subjetividade de González Rey (2003, p. 240). Rey explica que a subjetividade, vista sob o enfoque histórico-cultural, "se orienta para uma apresentação da subjetividade que em todo o momento se manifesta na dialética entre o momento social e o individual".

Em outras palavras, na indissociabilidade entre o individual e o social é que se constrói o sujeito histórico-cultural. No caso do professor, como sujeito históricocultural, reveste-se de inequívoca importância que o momento social seja constituído por uma relação ternária entre academia, alunos de licenciatura e escola.

Nessa mesma direção, por fim, registra-se o segmento "aproximação efetiva entre os saberes, promovendo a formação continuada". Lembrando que a base de um DPC está assentada numa relação horizontal entre academia e mercado, essa constatação do grupo é bastante sinalizadora de que um trabalho desenvolvido nos moldes do PIBID/Português garante a construção de uma aliança, em especial, linguodidática, na medida em que rompe com a atitude dogmática e paternalista da universidade em relação à escola.

Sobre isso, Richter (2015, p.17) deixa bastante claro que, por meio de um procedimento formativo fundamentado em um DPC, é possível:

inverter o sentido das vozes, de modo que tudo começa com as questões levantadas a partir da própria prática linguodidática contextualizada. (...) Cabe ao profissional com função assessorial abrir-se para a palavra do colega escolarizador enquanto sujeito integral. Mas, por outro lado, cabe a este aprender a dizer em jargão profissional, sem o que não há como construir o indispensável espaço de assimetria sistêmica, nem mesmo entrar em enquadramento (RICHTER, 2015, p.17) 
Assim, considerando-se a voz da supervisora, ao dizer que a "aproximação efetiva entre os saberes" promoveu "a formação continuada", conclui-se não só o respeito à horizontalização e, portanto, a inversão do sentido das vozes, como também uma sinalização de assimetria sistêmica, dada, por um lado, no uso da ideia de aproximação e, por outro, no manejo de conceitos como o de saberes e de formação continuada no repertório da professora regente.

\section{Considerações finais}

O paradigma indiciário, como método investigativo, tem suas bases assentadas na semiótica médica, disciplina que permite diagnosticar, nas palavras de Ginsburg (1989, p. 151), "as doenças inacessíveis à observação direta na base de sintomas superficiais, às vezes irrelevantes aos olhos dos leigos".

No caso da investigação aqui proposta, pode-se dizer que o mesmo trajeto epistemológico foi trilhado. Na busca pela análise das atividades realizadas pelo subgrupo num comparativo com os fatores de enquadramento propostos pela THA, o que se pretendeu estava relacionado à identificação de indícios que pudessem marcar a existência de um DPC e, portanto, do reconhecimento de uma empatia profissional suficientemente consistente e madura capaz de proporcionar uma aliança didática sólida no desenvolvimento teórico-prático consciente, num paradigma sociointeracionista de ensino de língua materna.

Ë certo que a proposta do PIBID como um programa de fomento e valorização da formação docente não pode ser considerada a única possibilidade para o DPC, mas no caso do subprojeto PIBID/Português mostrou-se como um caminho possível e bastante significativo na construção de relações mais sólidas entre agências formadoras e mercado de trabalho, no gerenciamento da fragmentação profissional, nos problemas decorrentes da não-regulamentação da docência como profissão e na existência não só de condutas como de práticas constitutivas e exercitivas distintas numa mesma área de conhecimento, nesse caso, de língua materna.

Um dos grandes princípios do DPC é a horizontalização entre academia e mercado, isto é, o rompimento com a ideia paternalista e, por vezes, dogmática de que é na academia que se encontram as soluções e os princípios que devem reger à escola, cabendo a esta obedecer e seguir o que aquela determina.

$\mathrm{Na}$ contramão desse patriarcalismo, o DPC preconiza um trabalho que parta de um processo dialógico, bilateral, horizontal, ou seja, que, a partir de diagnoses iniciais e longitudinais, se leve em consideração as demandas da escola e a visibilidade recíproca entre academia e mercado.

Nesse sentido, é certo que a proposta do PIBID como um programa de fomento e valorização da formação docente não pode ser considerada a única possibilidade para o DPC, mas, no caso, o subprojeto PIBID/Português mostrou-se como um caminho possível e bastante significativo na construção de relações mais 
sólidas entre agências formadoras e mercado de trabalho, no gerenciamento da fragmentação profissional, nos problemas decorrentes da não-regulamentação da docência como profissão e na existência não só de condutas como de práticas constitutivas e exercitivas distintas numa mesma área de conhecimento, nesse caso, de língua materna.

\section{Referências}

ANTUNES, Irandé. Aula de português: encontro e interação. São Paulo: Parábola, 2003.

BATESON, Gregory. Mente e natureza: a unidade necessária. Rio de Janeiro: Francisco Alves, 1986.

BEZERRA, Maria Auxiliadora. Ensino de Língua Portuguesa e Contextos TeóricoMetodológicos. In: DIONISIO, Angela Paiva et al. (Org.). Gêneros textuais \& ensino. Rio de Janeiro : Lucerna, 2005.

BRASIL, Ministério da Educação e do Desporto. Secretaria de Educação Fundamental. Parâmetros Curriculares Nacionais: terceiro e quartos ciclos do ensino fundamental. Língua Portuguesa. Brasília/MEC/CSEC, 1998.

BRASIL. Lei de Diretrizes e Bases da Educação Nacional n. 9.394/96 Estabelece as diretrizes e bases da educação nacional. Brasília: Diário Oficial da União, 23 Dez. $1996 . \quad$ Disponível <http://www.planalto.gov.br/CCIVIL_03/leis/L9394.htm>. Acesso: 29 set. 2015.

BRASIL. Secretaria de Educação Básica. Orientações curriculares do ensino médio. Brasília. MEC/SEB, 2008.

CAPPELLE, Mônica Carvalho Alves; SILVA, Késia Aparecida Teixeira. A Teoria da Subjetividade e a epistemologia qualitativa de Gonzalez Rey como possibilidade teórico-metodológica nos estudos de Administração. In: ENePQ, 2013, Brasilia. ENEPQ. RIO DE JANEIRO: ANPAD, 2013.

CAVICHIOLI, Fabrícia. Interferência do enquadramento de trabalho nas representações sobre o ensino de leitura no contexto de formação inicial docente sob o entendimento da Teoria Holística da Atividade. 2012. Tese (Doutorado em Estudos Linguísticos) - Universidade Federal de Santa Maria, Santa Maria, 2012.

GATTI, Bernardete A. A Construção da Pesquisa em Educação no Brasil. Brasília: Plano Editora, 2002. Série Pesquisa em Educação.

GATTI, Bernardete A. et al. Um estudo avaliativo do Programa Institucional de Bolsa de Iniciação à Docência. São Paulo: FCC/SEP, 2014. Disponível em: <http://www.capes.gov.br/images/stories/download/bolsas/24112014-pibidarquivoAnexado.pdf>. Acesso em: set. 2015.

GINZBURG, Carlo. Mitos, Emblemas, Sinais: morfologia e história. Tradução de Federico Carotti. 2. ed. São Paulo: Companhia das Letras, 1989. 
GONZALES-REY, F. L. Sujeito e Subjetividade: uma aproximação históricocultural. São Paulo: Thomson Learning, 2003.

KIST, Liane Batistela. Limites e possibilidades para a implementação de uma proposta de tutoria no desenvolvimento de estágio curricular em cursos de licenciatura. 2007. Dissertação. (Mestrado em Educação) - Universidade Federal de Santa Maria, Santa Maria, 2007.

LUDKE, Menga. A pesquisa em educação ao encontro de sua complexidade. In: MONTEIRO SILVA, Ainda Maria (Org.). Educação formal e não formal, processos formativos e saberes pedagógicos: desafios para a inclusão social. Encontro Nacional de Didática e Prática de Ensino, Recife, p. 413-424.

LUHMANN, Niklas. Introdução à Teoria dos Sistemas. Petrópolis: Editora Vozes, 2009.

MIZUKAMI, M. G. N. Escola e desenvolvimento profissional da docência. In: GATTI, B.A. et al. Por uma política nacional de formação de professores. São Paulo: Editora Unesp, 2013. p. 23-54.

PEIRCE, Charles Sanders. Semiótica. São Paulo: Editora Perspectiva, 1977.

RICHTER, Marcos Gustavo; FREITAG, Felipe. Diálogos com Felipe Freitag: entrevista com o criador da Teoria Holística da Atividade, Marcos Gustavo Richter. In: V Fórum de Estudos Interacionistas (PPGL-CEPESLI-UFSM). Entrevista audiovisual transcrita e editada por Marcos Gustavo Richter. Universidade Federal de Santa Maria, 2015.

RICHTER, Marcos Gustavo. Formação de Professores, emancipação, profissionalização. In: Expressão, v. 1, n. 1, 2005, p.112-118.

RICHTER, Marcos. Profissionalização docente segundo a Teoria Holística da Atividade: estudo empregando software de mapeamento semântico. In: LEÃO, Rosaura Albuquerque; MOTTA, Vaima Regina Alves (Org.). Linguagem e Interação: o ensino em pauta. São Carlos: Pedro e João Editores, 2011.

STAKE, Robert. Investigación com estudio de caso. 4. ed. Madri: Ediciones Morata S. L., 2007.

STEINHILBER, Jorge. Profissional de Educação Física... existe? Rio de Janeiro: Sprint, 1996.

ZEICHNER, K. M. Repensando as conexões entre a formação na universidade e as experiências de campo na formação de professores em faculdades e universidades. Educação. Santa Maria, RS, v. 35, n. 3, p. 479-504, dez. 2010. Disponível em: <http://cascavel.ufsm.br/revistas/ojs2.2.2/index.php/reveducacao/article/view/2357/1424>. Acesso em: out. 2015.

ZUIN, Poliana Bruno; REYES, Claudia Raimundo. $O$ ensino da língua materna: dialogando com Vygotsky, Bakhtin e Freire. Aparecida: Ideias \& Letras, 2010. 